\title{
PREVALENCE OF TYPES OF BENIGN BREAST LESIONS, BY AGE GROUP, IN GOIÁS
}

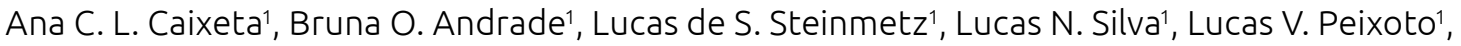
Matheus L. T. Costa', Júlia J. Caetano', Vitória N. Macedo

'Universidade Federal de Goiás - Goiânia (GO), Brazil.

Objective: To carry out a study of the prevalence of benign breast lesions, by age group, in Goiás, establishing the types that most affect certain ages. Methodology: This is a descriptive study of DATASUS data regarding histopathological examination of the breast in the years 2010 to 2013, in Goiás. Results: Fibroadenoma with 652 cases is the most prevalent benign lesion, with the highest age group of 15-19 years, with a small decrease of 20-24 years, remaining stable until the age of 49 and regressing thereafter. There was a decrease from 2011, with 197 cases, to 111 cases in 2013. Fibrous condyloma with 235 cases, with an age group with major involvement between $45-54$ years (37.44\%), is stable between 30-44 years and increase to 45 years with a subsequent decrease after 54 years. There is stability between the number of cases in 2010 (61 cases) and 2011 (68 cases), leading to a small decrease until 2013, with 43 cases. Adenosis WOS (without other specifications) type lesions, with 75 cases, were more prevalent in the 40-54 age group (52\%), with small involvement among the young, observing an increase in adult cases and regression in the elderly. There is a decrease in cases between 2010 (27 cases) and 2011 (15 cases), remaining stable until 2013 (15 cases). The ductal hyperplastic lesion without atypia, with 62 cases reported, showed a stability in the number of cases between 30-49 years, with increase between 50-54 years (14 cases) and subsequent decrease between 55-69 years. There is a considerable decrease between 2010 and 2011 (from 23 to 13 cases), with a stabilization until 2013, where 11 cases were reported. Conclusion: It is possible to note that the cases that were most reported in Goiás between 2010 and 2013 were, in order of higher prevalence, fibroadenoma, fibrous condyloma, adenosis WOS and ductal hyperplastic lesion without atypia. The most prevalent age group in the observed cases was 40-54 years, except in fibroadenoma, the highest prevalence in adolescents (15-19 years). In the period between 2010 and 2011, there was an increase in cases of fibrous condyloma and a decrease in the cases of adenosis WOS and ductal hyperplastic lesion, in the same period. As of 2011, there was a decrease in cases of fibroadenoma. In 2013 there was a reduction in cases of fibrous condyloma. The number of cases of adenosis WOS and ductal hyperplastic lesion without atypia remained stable in the same period. 